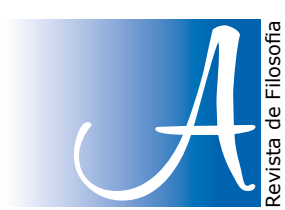

ARGUMENTOS

\title{
A música como arte imitativa: da estética cartesiana à arte de expressar paixões
}

Music as imitative art: from Cartesian aesthetics to the art of expressing passions

\section{RESUMO}

A Querela dos Bufões, que durou de 1752 a 1754, e colocou a tradição operística francesa contra a italiana serve de pano de fundo para o artigo. Rameau foi acusado de estar ultrapassado, e sua música, de ser complicada demais, em comparação com a "simplicidade" e "naturalidade" da ópera cômica La Serva Padrona, de Pergolesi. Em meados de 1750 Rameau criticou os verbetes sobre música que Rousseau havia escrito para a Encyclopédie, levando a uma disputa com os filósofos D'Alembert e Diderot.

Palavras-chave: Música. Arte imitativa. Paixões. Melodia. Harmonia.

\section{ABSTRACT}

The Quarrel of the Buffoons, which lasted from 1752 to 1754, and set the French operatic tradition against the Italian, serves as a backdrop to the article. Rameau was accused of being outdated, and his music too complicated, compared to the "simplicity" and "naturalness" of Pergolesi's La Serva Padrona comic. In the mid-1750s Rameau criticized the music entries Rousseau had written for the Encyclopédie, leading to a dispute with philosophers D'Alembert and Diderot.

Keywords: Music. Imitative art. Passions. Melody. Harmony.

\section{Introdução}

Quando evocamos a figura de Jean-Philippe Rameau, a maior parte dos músicos e aficionados recordam a sua contribuição na ópera, sua obra para o cravo e, na teoria, seu conhecido Tratado de harmonia de 1722, primeira obra com esse

\footnotetext{
* Doutor em Filosofia e professor associado ICA-UFC. https://orcid.org/0000-0001-8940-1545
} 
título na história musical. No entanto, poucos sabem que o tratado foi apenas o primeiro de uma mente teórico musical de primeira ordem, cuja produção restante forma uma lista de meia dúzia de títulos importantes, além de artigos, cartas e opúsculos.

Embora a prudência recomenda dissociar o artista do teórico, o gênio musical e o pensador, ${ }^{1}$ não surpreenderá certamente o fato de Jean-Philipe Rameau ter sido condenado por ter exercido um pensamento filosófico sobre a sua arte, e por ter assim ultrapassado os supostos limites naturais do artista. ${ }^{2}$ Participou em querelas com os seus contemporâneos, dos quais os mais aguerridos e violentos eram precisamente os filósofos, os intelectuais que defendiam a tese do "sensualismo" - entre eles Jean-Jacques Rousseau, filósofo artista.

Rameau personificou, de forma exemplar, aquilo a que D'Alembert chamou o artista filósofo (LEGRAND, 2007, p.9). Procurando uma fundamentação para a música, Rameau produziu um discurso científico que seguia exemplarmente o método cartesiano. E, apesar do argumento crítico de Rousseau, segundo o qual tudo se passa nos "corações", a questão parece persistir. A querela mantém-se viva, pois são numerosos aqueles que creem deverem os artistas excluir-se do exercício da razão. Rameau, numa época de não autonomia da arte, ${ }^{3}$ afirmava o direito dos artistas à razoabilidade.

O uso do entendimento e da razão tinha aliás algo de voluptuoso - aquele que o usava fazia-o num ato de independência. A autonomia da arte joga-se, portanto, também ao nível do pensamento que é possível produzir sobre ela, joga-se ao nível do reconhecimento do direito dos artistas a produzirem um discurso autorizado sobre a sua arte, a exercerem a razão, ou seja, a pensarem. Reconhecerse-á, talvez, em toda esta questão, o antagonismo tão caro a Nietzsche entre o "espírito apolíneo" e o "espírito dionisíaco"; de fato, é Nietzsche quem assinala esse antagonismo fundamental da cultura grega "entre a arte do figurador plástico (Bildner), a apolínea, e a arte não-figurada (unbildlichen) da música, a de Dionísio" (NIETZCHE, 1996, p.27). Arte sem formas e, por isso, com todas as formas que o entusiasmo dionisíaco lhe moldasse, a música conheceu também racionalizações que ultrapassavam o pacifismo ecológico do "som idílico das flautas dos pastores", mesmo nesse tempo quase mítico dos gregos.

Pitágoras lançou os primeiros fundamentos de uma ciência dos sons, ignorava como o ouvido se apercebia das relações entre as notas, enganou-se nos seus limites, mas descobriu que a sua percepção era a fonte do prazer musical. Aristoxenes, por outro lado, baniu da composição os números e o cálculo e remeteu ao ouvido a tarefa de escolher as consonâncias. Pitágoras e Aristoxenes

\footnotetext{
${ }^{1}$ Ser intelectual, no século XVIII, é motivo de prestígio e não fonte de vergonha. No entanto, e apesar de tudo, a condição de intelectual não era suficientemente bem vista num artista. Rameau foi responsável por um pensamento e por uma ação - ele foi teórico e compositor. O inverso também era verdadeiro: Rousseau e Voltaire, por exemplo, mais conhecidos pelas suas obras literárias e filosóficas, também compuseram música e escreveram librettos de óperas (Cf. DOUS, 2011, p.13-43)

${ }^{2}$ Raphaëlle Legrand ressalta a existência de "dois caminhos paralelos" com objetivos distintos nas obras teóricas e musicais de Rameau. Em termos gerais, "é imprudente analisar sua música unicamente à luz de sua teoria, como explicar sua evolução intelectual a partir apenas da observação da obra musical" (LEGRAND, 2007, p.1 1).

${ }^{3}$ Seria preciso esperar até Mozart para encontrarmos o primeiro músico revoltado, talvez autônomo (mas ainda não intelectual ou filósofo); mas, especialmente Beethoven a quem repugnava escrever por encomenda e recusava violentamente o "serviço" na Corte e na Igreja. A sua atitude face à composição musical introduziu a revolução da liberdade criativa, desconhecida até aí.
} 
eram os filósofos que se opunham (o racionalismo contra o empirismo: o apolínio e o dionisíaco). ${ }^{4}$ A história parece assinalar a constância deste dualismo. Mas seria demasiado pobre aceitá-lo simplesmente. Até porque, de certa forma, o projeto de Rameau poderia ter posto fim à questão, como veremos, seguindo o programa de uma "estética cartesiana". Ele pensava cartesianamente e tornou-se assim uma figura exemplar do espírito francês que não reconhecia outra autoridade senão a da sua própria razão. Neste aspecto, a sua contribuição essencial foi o de restabelecer os direitos da razão, por meio da dúvida. Rameau pensava a inteligibilidade da sua arte. Amante das coisa da inteligência, levava até à extravagância um certo espírito de geômetra - a geometria refinada e rigorosa dos jardins franceses e da construção harmônica da música. Espírito este que nos permite levantar a questão de saber se existirá um cartesianismo estético, pois da união do homem de ciência com o homem de arte surgirá certamente o homem de gosto (o artista ideal, o artista com um coração inteligente).

Se aceitarmos esta síntese como parte do programa de uma estética cartesiana, poderemos sem grande dificuldade reconhecer em Rameau uma manifestação evidente da independência da racionalidade moderna. Com o Discurso do Método, Descartes produziu, em última análise, uma declaração de autonomia da razão. Assim, o autor não aceita o recurso à observação direta e ingênua, aderindo antes a uma visão do mundo segundo a qual "a verdade dos fenômenos se esconde atrás da aparência sensível imediata" (KINTZLER, 1988, p.21). Por consequência, o músico, ao aceitar as sensações puras, sujeita-se a não se aperceber mais do que da aparência do som. A aparência, mas não as suas leis, os seus princípios abstratos, a sua imaterialidade. ${ }^{5}$

Ao afirmar como máxima "nihil est in intelecto quod non ante fuerit in sensu" o sensualismo veda-se ao verdadeiro conhecimento, àquele que diz respeito à verdade que se esconde por detrás da aparência dos fenômenos. Preparado para ver as aparências, o sensualismo deixa escapar a verdade e embarca na contradição fatal que lhe não permitiria "ver" as ideias de Deus e de alma, que são suficientemente intangíveis e in-aparentes para poderem ser apercebidas pelos sentidos. Descartes protesta contra aqueles que nunca levam o seu espírito "para além das coisas sensíveis", contra aqueles que não veem o inteligível se este não for imaginável:

E isto é assaz manifesto pelo fato de os próprios filósofos terem por máxima, nas escolas, que nada há no entendimento que não haja estado primeiramente nos sentidos, onde, todavia, é certo que as ideias de Deus e da alma jamais estiveram. (DESCARTES, 1973, p.57).

\footnotetext{
${ }^{4} \bigcirc$ antagonismo não desaparece, embora cada época procure resolvê-lo ou geri-lo. A música contemporânea, afogada em todos os excessos, oscilou no final do século passado (o XX) entre um minimalismo autista e um abstracionismo a-social. E há sinais também de que um certo cartesianismo estético perdura nas obras de uma música (e uma arte) apolínea e cândida que deixou de se preocupar com aquilo que é preciso dizer e assim procura a todo o custo despolitizar a sua existência - assumindo neste caso o tom da regressão. Nomeadamente nas propostas de compositores que apresentam sínteses da tradição clássica e da moderna, corruptelas geralmente bem toleradas por um público que se sente assim a penetrar num universo de que se sente frequentemente excluído pelo mundo da cultura, ou do qual modestamente se auto-exclui.

${ }^{5}$ André Charrak oferece um bom debate sobre as operações filosóficas na música, em especial, da relação Descartes-Rameau (CHARRAK, 1998, p.39-45).
} 
Segundo o método, Rameau sustenta, como verdadeiro homem das Luzes, que, para observar a natureza tal como ela é, é preciso armar-se de instrumentos matemáticos, já que os olhos são impotentes para mostrar o que está vedado, coberto pelo véu opaco das aparências. A experiência é má conselheira, não permite atingir o verdadeiro conhecimento nem, por conseguinte, permite tocar a essência ordenadora da música. Se os olhos não são suficientes para o físico, ao músico também não bastará o ouvido.

Sem conceito e sem princípios o conhecimento tateia como um cego e não pode conhecer senão aspectos pontuais. Rameau inspira-se na lição de Galileu e de Descartes: é preciso dissociar abstratamente os parâmetros invisíveis que se conjugam na realidade empírica para que se consiga construir o princípio, a lei. $O$ ouvido é capaz de fornecer um determinado tipo de conhecimento, mas não vai para além de algumas indicações parciais e confusas que o músico só pode reter sob a forma de receitas. Trata-se de um conhecimento arbitrário, diz Rameau, porque a partir dele não é possível produzir relações teóricas entre os fenômenos que são tomados como objetos. Mais exatamente, é um conhecimento que não pode entrar numa ordem razoável. Este é o conhecimento que se adquire aprendendo de cor (ou seja, aprendendo pelo coração) e que é governado exclusivamente pelo acaso. O objetivo que o move é, pois, o de "restituir à razão os direitos que perdeu dentro do campo da música". Rameau desdenha claramente da experiência, pois ela e as regras que dita não oferecem garantia de um conhecimento totalizante. Por isso, ele pede aos músicos que desconfiem do seu ouvido, como primeiro passo para um conhecimento mais aprofundado sobre a sua arte; conhecimento da sua verdade por meio do método da dúvida.

É neste contexto de imersão intelectual e teórica que Rameau desenvolve a sua teoria da geração harmônica sustentada por bases científicas, a partir de estudos de acústica e da fisicalidade da matéria sonora, já que só a razão poderá revelar os mistérios ocultos por detrás das aparências. O que descobriu, como um cientista descobre, foi a naturalidade da conjugação harmônicas dos sons - a harmonia. Em suma, o conjunto de regras e leis (naturais) de harmonização dos sons.

\section{Influências de Descartes}

Nas Considerações Prévias do seu Compendium Musicae, Descartes afirma que "todos os sons podem provocar algum prazer", 6 e continua:

$\left[2^{\circ}\right]$ Para este prazer é necessária uma certa proporção do objeto com o mesmo sentido. Daí que, por exemplo, o estrepito dos mosquetes e dos trovões não pareça apropriado para a Música: porque, evidentemente, causaria dano aos ouvidos, tal como o excessivo resplendor do sol aos olhos se estes o contemplarem de frente [...]. (DESCARTES, 1987, p.56).

\footnotetext{
${ }^{6}$ Mas o verdadeiro segredo do bom senso e da razoabilidade cartesiana está nos seus quatro preceitos: "Nunca aceitar como verdadeira qualquer coisa sem a conhecer evidentemente como tal [...]. Dividir cada uma das dificuldades que tivesse de abordar no maior número possível de parcelas que fossem necessárias para melhor as resolver. Conduzir por ordem os meus pensamentos, começando pelos objetos mais simples e fáceis de conhecer [...]. Fazer sempre enumerações tão completas e revisões tão gerais que tivesse a certeza de nada omitir" (DESCARTES, 1973, p.45-46).
} 
A reivindicação de uma justa proporção para a música é a afirmação da negação de todos os excessos do sensível (do estético) e vem retomar Aristóteles (ARISTOTE, 2014, 426a) que afirmava que o excesso num som, tanto agudo como grave, destrói o ouvido; o excesso dos sabores, destrói o gosto; o excessivamente brilhante ou obscuro destrói a vista; em suma, os excessos nos sentidos ultrapassam os limites e provocam dor e destruição. Este aspecto, que é verdadeiramente importante em Descartes, vem de fato colocar à vista algumas das premissas essenciais do seu pensamento estético, em grande medida construído sobre a música ${ }^{7}$ - uma arte exemplarmente invisível. O pensamento cartesiano abre caminho a uma ciência musical com renovada energia. Foi, pois, a partir destas premissas que Rameau, fazendo um uso criterioso da razão e por um trabalho de desvelamento das aparências teorizou e realizou aquilo a que Kintzler chama o "cartesianismo estético".

A questão, como vimos, gira em torno do debate que opunha sensualistas e intelectualistas. Rameau, apoiando-se em Descartes, repudia todos os excessos sensuais de uma música que ele entrevê como um fenômeno racionalizável capaz de aceder ao nível de uma ciência. A posição de Rameau não pode ser entendida senão como fruto de uma concepção do mundo, do homem e da arte que é preciso nomear: a filosofia de Descartes. É ela que sustenta o "esplendor da estética do prazer no classicismo"8 e a teoria da tragédia lírica, segundo Kintzler, a partir de quatro axiomas: o primeiro axioma pressupõe que a verdade da natureza é sempre abstrata e assente em relações formalizáveis - axioma intelectualista do conhecimento. $O$ segundo destaca a ilusão como artifício revelador da verdade - axioma sensualista da ficção teatral. O terceiro axioma afirma que a tragédia lírica foi pensada como duplo e como inverso da tragédia dramática - é o axioma do teatro dos encantamentos. O quarto axioma estipula a constância da relação material entre a música e a língua articulada, a co-presença incessante entre os significantes da língua e os sons da música - é o axioma da necessidade do recitativo e da articulação da música.

Quatro axiomas, enumerados do geral ao particular. Mas, o seu oposto, na crítica de Rousseau (que evidentemente não conhecia esta formulação), vê nela um obstáculo à comunicação pura. Rousseau critica Rameau precisamente todos os valores clássicos "luzes, conhecimentos, leis, moral, razão, benevolência, consideração, suavidade, amenidade, cortesia, educação" (KINTZLER, 1987, p. 149), e rejeita nele a sua capacidade de tratar as paixões como ilusões. Rousseau não é apenas um crítico da música francesa e do seu estado harmônico, refinado e degenerado: ele produz uma crítica global à estética clássica, precisamente por meio

8 Compendium Musicae foi escrito, como já foi referido, na juventude do autor (1618, com 20 anos) e era dedicado a Isaac Beeckman, como presente de Ano-Novo. Beeckman, físico-matemático, dava aliás grande importância ao estudo da música e da acústica, pois considerava que a "ciência musical era por excelência o domínio ideal para o desenvolvimento do seu pensamento (as suas investigações musicológicas dedicavam-se então à definição física das consonâncias, à explicação do prazer do ouvido, e à teoria dos modos)". Na realidade, o Compendium Musicae só se tornou conhecido após a sua publicação póstuma (1650), podendo talvez ser considerado como uma espécie de prelúdio da sua última obra, As Paixões da Alma. Uma relação parece ser evidente: entre o lugar que ocupa a questão do ritmo e da medida (da proporção e do equilíbrio), no Compendium, e a apologia da sagesse que deve marcar o ritmo adequado de viver de modo plausível, em As Paixões da Alma. 
do objeto mais visível e espetacular que ela produziu: a ópera, o espetáculo, o lugar privilegiado da ilusão. É possível que, apoiando-se sobre uma leitura regressiva de Rousseau, os apóstolos modernos da alma sensível tenham recusado as delícias do espírito e da magnificação do corpo, para sequestrar a música dentro do campo fechado da espiritualidade. Mas, a síntese mostrou ser possível, tanto do ponto de vista técnico, como estético, como filosófico.

Este é pois um dos mais fortes antagonismos que vem atravessando a história de um pensamento sobre a música, diz respeito à eterna disputa entre uma estética do prazer e dos sentidos e uma estética dirigida à inteligência, como fruto da racionalização daquilo que tão naturalmente parece pertencer ao domínio exclusivo das sensações. A possibilidade da derrota da primeira pela segunda - pelos avanços crescentes de um pensamento reflexivo sobre a arte e os seus modos de ser e de fazer - surge como uma questão central de uma polêmica que parece não ter fim e que, em cada momento da história, opõe os mesmos antagonistas. E, dado que não foi possível, até agora, encontrar um modo de fechar este debate, ou se aceita que ele não tem um fim ou, pelo contrário, se aceita que ele propõe dois modos coexistentes e que, portanto, não se excluem mutuamente. Ou ainda que uma boa gestão dos dois daria o resultado mais razoável e sensato: o artista ideal como parece ter ficado demonstrado com o romantismo e, em especial, com o projeto programático de Wagner, o artista que possui um coração inteligente.

\section{Da estética cartesiana à arte de expressar paixões}

A questão central colocada pela dúvida racionalista e cartesiana de Rameau é a seguinte: por que razão haveria a música de escapar às leis que regem os (outros) fenômenos da natureza? ${ }^{9}$ De uma resposta positiva a esta questão emerge uma segunda: a harmonia parece ser uma decorrência natural do caráter físico do som como fenômeno acústico. Mas, por outro lado, ela é também a racionalização dos recursos acústicos que a natureza coloca à disposição dos compositores: os sons musicais ${ }^{10}$. Por esse motivo, talvez se pudesse falar de duas harmonias ${ }^{11}$ : uma, a natural, que existiria em estado puro no fenômeno físico da ressonância dos corpos e que potencia a outra, a digamos "artificial", que resulta do estudo da primeira e da sua conversão em tratados e num severo conjunto de regulações que conduziram historicamente a uma música que passa a dever ser composta de uma certa forma, segundo esses cânones, isto é, segundo os princípios abstratos

\footnotetext{
${ }^{9}$ A ópera como espetáculo e espaço social de ilusão, cênica e social, de fato. As estruturas institucionais da monarquia centralizada favoreciam e mantinham a existência de uma ópera magnífica e luxuosa, espetáculo total necessariamente subvencionado.

10 Os sons e a sua possibilidade estão na natureza, na voz humana a música teria surgido na modulação dos sons e na forma como as línguas naturais desenvolveram uma prosódia própria.

${ }^{11}$ No Tratado de Harmonia, Rameau afirma que a melodia é derivada da harmonia: "Divide-se ordinariamente a música em harmonia e melodia, embora esta não seja senão uma parte da primeira, e baste conhecer harmonia para estar perfeitamente instruído sobre todas as propriedades da música [...]" (RAMEAU, 2009, p. 1). Embora já contenha importantes contribuições à harmonia, como a noção de baixo fundamental e as inversões dos acordes, foi em obras posteriores que Rameau estabeleceu uma base teórica mais consistente, em especial, na Demonstração do Princípio da Harmonia de 1750. Nesta obra, o fundamental principal é o fenômeno físico da ressonância dos corpos.
} 
que regem as relações naturais entre os sons. Com efeito, e seguindo esta lógica, estaríamos perante um quadro que pensa uma música certa e outra incerta: uma, que respeita o caráter natural e físico dos sons e das suas relações, e que retira a música ao arbítrio da razão e aos desígnios do sujeito criador; outra, que foge à naturalidade e à ideia de uma comunicabilidade pré-determinada pela natureza. A origem de um pensamento sobre a música (ou se quiserem: de uma filosofia da música), corresponde em grande medida ao início da consciência do funcionamento da música, ao momento em que a música se torna objeto.

Este mesmo antagonismo dá lugar a outro: a evolução da ópera esbarra na mesma altura com uma polêmica que opõe os defensores de uma primazia da música em relação à linguagem articulada, aos defensores do seu oposto. Tomou corpo na conhecida Querela dos Bufões, ${ }^{12}$ episódio em que se manifestou a oposição entre as teses sensualistas e intelectualistas: Rameau e Rousseau (os "do lado do Rei" e os "do lado da Rainha"). Esta querela tem, no fundo, uma mesma raiz.

Rousseau, que defendia uma gênese comum para a linguagem ${ }^{13}$ e para a música, afirma a tese de que originalmente, num tempo miticamente anterior, "um anterior irreal" (na expressão de Catherine Kintzler, 1988), as línguas e a música primitivas eram feitas para seduzir e emocionar, enunciando aquilo a que hoje se chamaria a tese da transparência e da comunicabilidade. Isso permitiria revelar duas propriedades essenciais da "música-poesia" originais: em primeiro lugar, uma natureza emotiva - visto que diz respeito diretamente ao coração e às paixões; em segundo lugar, é da ordem de uma comunicação imediata - é uma forma de circulação das emoções que vão de um coração a outro pelo caminho mais direto - permitindo uma "penetração recíproca".14

Esta tese é sustentada pelo pressuposto de um "anterior irreal" que, embora não seja demonstrável, autoriza ainda assim Rousseau a ir mais longe: para ele a música é originalmente melodia, e a sua gênese é pré-harmônica, visto que ela teria nascido em simultâneo com as línguas naturais, das quais se teria separado a partir de um processo gradual de emancipação da prosódia. ${ }^{15}$ Ele invoca esse

\footnotetext{
12 Em cada época a noção de som musical parece ganhar diferentes significados. Dos sons produzidos pela voz humana, passando pelas percussões, pela flauta, a arpa, pelo órgão, até aos nossos dias em que, para além dos sons de síntese provenientes da manipulação eletrônica, se admitem como sons musicais todo um invulgar conjunto de sons: sirenes, o quotidiano urbano, a natureza, em suma todos os sons que podem ser tornados obra segundo a lógica composicional e segundo a convenção que cada obra propõe.

13 Episódios da Querelle des Bouffons tiveram lugar no próprio teatro de Ópera de Paris a partir de 1752 (-1754) e declarou-se na sequência da representação da ópera de Destouches, Omphale, que foi acusada de representar tudo o que era artificial e démodé na ópera francesa. Mas, foi a apresentação da ópera-buffa de Pergolesi, La serva padrona (1733; Paris em 1752), que extremou os contendores: artistas, intelectuais e filósofos partidários da música italiana, contra artistas, intelectuais e filósofos que acreditavam na possibilidade de um renascimento do teatro lírico francês. Contra a ópera de Rameau opunham a ópera-buffa italiana. A divisão entre os dois campos era real: de um lado ceux du coté du Roi (os adeptos da ópera francesa, Madame de Pompadour e Rameau), do outro ceux du coté de la Reine (os partidários da ópera italiana, Rousseau, Diderot e D'Alembert)

${ }^{14}$ Neste sentido, Rameau, para poder tratar a música como um meio capaz de despertar emoções, deveria fazer uso da "mecânica cartesiana das paixões", verdadeira engenharia da comunicabilidade musical.

${ }^{15}$ A expressão é de Rousseau aplicada por analogia: "Avant que l'art eût façonné nos manières et appris à nos passions à parler un langage apprêté, nos moeurs étaient rustiques, mais naturelles; et la différence des procédés annonçait au premier coup d'oeil celle des caractères. La nature humaine, au fond, n'était pas meilleure; mais les hommes trouvaient leur sécurité dans la facilité de se pénétrer réciproqement, et
} 
estado original com vista à sua reposição, de forma coerente, aliás, com a ideia de uma música originalmente boa, tal como se supunha a existência de um "bom selvagem". Esta perspectiva implica evidentemente considerar a subordinação da música e da sua lógica à lógica superior da linguagem articulada - posto que a música seria afinal o resultado da independência da melodia rudimentar e monódica que subjaz às entoações e inflexões da fala e que, portanto, seria tarefa da razão repor a situação original.

Esta questão é essencial. Discutir uma origem da língua implicaria, de fato, encontrar ao mesmo tempo uma origem para a música. O problema, no fundo, encerra o seguinte paradoxo: como colocar a questão da origem de algo que está afinal na origem de todas as questões? A resposta não é afinal uma resposta, visto que sem língua não há razão e que sem razão não há língua. Este ciclo aparentemente infinito conduziria a uma discussão ociosa e infrutífera, sobretudo porque a demonstração não é possível. Mas, para a Querela impunha-se um argumento definitivo, isto é, um argumento que fundamentasse o ponto de vista da melodia como resultado da independência da prosódia: essa fundamentação, essencial para o conceito de ópera, só poderia ser encontrada numa origem.

A música, como as línguas primitivas, eram, antes de tudo, resultado das paixões e não tanto da necessidade, admitindo como início uma "voix passionnée", fato primitivo e na essência humano. A dissociação entre articulação e modulação é extremamente importante, pois é ela que vai permitir a Rousseau formular a teoria da degenerescênia paralela da música e das línguas. Há uma recusa para a música de outra ordem que não seja a da sedução e da emoção, ou seja, dos sentimentos e do coração. A sua teoria da modulação concebe uma ideia de língua absoluta, um pouco como uma língua que tivesse apenas significado e não tivesse significante.

É a abstração de uma língua imediata e transparente: a música, afinal, a única capaz de operar entre os homens (seres individuas e divididos) a possibilidade de uma "penetração recíproca", como vimos. Mas, por outro lado, dado que essa língua possui um órgão obrigatório que é a boca, e sendo a música a emancipação da melodia original, então é a voz o primeiro meio, que sofre modificações (modulações) pelo efeito da língua ou da glote, segundo as paixões que a movem: para a língua, a agressividade, (ROUSSEAU, 1995, p.410-412) a cólera, a desconfiança - onde predominam as consoantes; para a glote, a piedade e a benevolência (é ela que origina a fala-melodia, pela acentuação e inflexão da voz) - onde predominam as vogais, num jogo musical entre sons curtos e longos, com variações de altura e de timbre. ${ }^{16} \mathrm{~A}$ inversão deste ponto de vista é, pois, evidente. Se falar é cantar, cantar também é falar, e assim, para Rousseau, uma vez que a ópera

cet avantage, dont nous ne sentons plus le prix, leur épargnait bien des vices." (ROUSSEAU, 1964, p.47). $\bigcirc$ que parece, para além do mais, demonstrar, sob a forma de uma nostalgia otimista, por assim dizer, o desejo de um reencontro com a possibilidade da comunhão que Rousseau não cessa de ver numa origem ("un 'avant' iréel").

${ }^{16}$ Como sublinha Kintzler (1987, p. 138), Rousseau vê aqui a origem das línguas do Norte, secas e imperiosas e portanto não musicais, pois, segundo ele: "On n'avait rien à faire sentir, on avait tout à faire entendre; il ne s'agissait donc pas d'énergie, mais de clarté" (ROUSSEAU, 1995, p.407-408). Esta observação de Rousseau antecipa, a partir das línguas do Norte (ou seja, necessariamente para ele, também da música do Norte), a atitude que a arte moderna viria a suscitar mais tarde: o entendimento, contra o sentimento. 
"fala", o seu discurso e as suas falas deverão ser sustentados por uma prosódia natural, uma melodia adequada com precisão à expressão das emoções.

Rousseau, protesta ainda contra os artifícios harmônicos das obras de Rameau, que coloca a música e os seus efeitos em primeiro plano. A teoria de Rameau implica uma visão materialista da música, entendida como um conjunto de relações de fenômenos sonoros, ou seja, como um fenômeno físico independente, na sua natureza essencial, mas análoga na sua estruturação harmônica à composição material das línguas faladas pelos homens. Rousseau, pelo seu lado, vê na música um fenômeno de comunicação, um fenômeno da ordem da linguagem, defende e propõe uma música tal como ela deveria ter sido ${ }^{17}$ - uma melodia ideal. A melodia (ideal), pela sua relação imediata à substância do coração e às paixões da alma, faz da música uma arte íntima: ela não imita objetos, ela imita sentimentos. Mas, as mediações sociais produzem os seus efeitos: depois da separação, música e língua seguem caminhos diferentes, estruturam-se e complexificam-se. A música, tal como ela é, "harmonizando-se, instrumentalizando-se, intelectualizando-se, perde a sua qualidade de signo transparente" (KINTZLER, 1987, p.143). Ela transforma-se em coisa e reduz-se à combinação abstrata dos sons.

Uma teoria negativa da harmonia, tal como surge em Rousseau no Ensaio sobre a origem da língua, torna evidente uma sua propriedade essencial - a sua opacidade: Rousseau não recusa o fundamento natural das leis da harmonia; ele recusa antes o seu valor estético. Uma crítica moderna a esta questão faria, no entanto, ressaltar justamente o valor de um acorde, de uma cadência e de um encadeamento harmônico, visto que a percepção estética e a socialização dos fenômenos sonoros passou a aceitar essa retórica das figuras musicais segundo uma posição inicial muito precisa. A título de exemplo, poderia dizer-se que a prática musical tem demonstrado que o modo menor tem sido utilizado em especial para conseguir comunicar tristeza e recolhimento, e o modo maior para exprimir alegria e esperança; que existe a expectativa de que que a tensão provocada pelo acorde de sétima da dominante seja resolvida no acorde da tônica; que uma cadência perfeita cria a sensação de um final; etc.

São algumas convenções que refletem um clima semiológico e uma ordem linguística a que a música acedeu. A questão é, aliás, muito pouco original. Já Descartes, no seu Compendium Musicae, afirmava:

$\mathrm{Na}$ verdade, esta quietude ou cadência não resulta agradável apenas no final, mas também no meio da melodia; a fuga desta cadência proporciona um prazer estimável, quando uma parte parece que quer descansar enquanto que a outra avança mais além. E este género de figura é na música algo parecido ao que as figuras retóricas são no discurso [...]. (DESCARTES, 1987, p.134).

\section{Conclusão}

Durante alguns séculos, a harmonia manteve-se inquestionavelmente na base das formas aceites de fazer música - afinal as formas que ainda hoje predo-

${ }^{17}$ Modelos de teorização das relações entre a música e a linguagem verbal. 
minam na música corrente. Mas, a atração por uma crescente complexificação dos materiais sonoros veio a desregrar o que era norma e essa harmonia tradicional foi perdendo importância. "A possibilidade da própria música tornou-se incerta", diz Adorno (ADORNO, 1973, p.112), comentando esse momento crítico da viragem em que a crise era o reflexo do carácter a-social e não harmônico da música, cercada pela suspeição dos seus destinatários.

Como nota também Adorno, a "decadência individualista" dos compositores da viragem veio a levantar de novo a mesma questão, pois, segundo as suas palavras,

por meio da hostilidade em relação à arte, a obra de arte aproxima-se do conhecimento. Desde o princípio, a música de Schönberg andou próxima da cognição. Foi isto e não a dissonância a base para a sua rejeição o que deu lugar ao grito estridente contra o intelectualismo. (ADORNO, 1973, p.124).

Esta recusa do intelectualismo da música de Schönberg, e como reação ao modernismo musical, encontra o seu fundamento de novo nas teses da naturalidade da música. Henri Pousseur, ao discutir precisamente as relações entre música, semântica e sociedade, defende que apesar de certa concepção musical e até mesmo certa prática pretende nos fazer crer, os sons não são entidades independentes, separadas do resto da realidade e capazes de serem utilizadas sem levar em conta este fato. (POUSSEUR, 2005, p.57). O que poderia querer dizer que Schönberg estaria afinal a compor uma música anti-natural, uma música incerta, ou mesmo errada, uma música que respeitava outras leis, que não as da natureza, ou nenhumas, ou simplesmente as leis ditadas por cada obra, recusando aquilo que a natureza impõe e que está de acordo com a fisicalidade, a naturalidade da audição e com os mecanismos da socialização. Desta maneira, acrescenta Pousseur, devido à sua natureza "pitagórica", as estruturas harmônicas mantêm uma relação de princípio fundamental com as noções essenciais e determinantes da realidade material (por exemplo, com estruturas onduladas, atômicas ou moleculares). (POUSSEUR, 2005, p.59). Esta relação próxima e inevitável, este caráter natural, é porém contrariado por um outro fenômeno de ordem diferente: a audição estética, ou seja, aquela que tem como expectativa ouvir sons organizados e emitidos intencionalmente respeitando os códigos que vigoram num determinado contexto social de audição.

\section{Referências}

ADORNO, T. Philosophy of modern music. Translated from German by Anne G. Mitchell and Wesley V. Blomster. New York: The Seabury Press, 1973.

ARISTOTE. De l'âme. In Euvres complètes. Traduit par Richard Bodéüs. Paris: Flammarion, 2014.

CHARRAK, A. Musique et philosophie à l'âge classique. Paris: PUF, 1998.

DESCARTES, R. Discurso do método. In Os Pensadores. Tradução de J. Guinsburg e Bento Prado Jr. São Paulo: Abril Cultural, 1973. 
. Abrégé de musique. Compendium musicae. Traduit par Frédéric de Buzon. Paris: PUF, 1987.

DOUS, J-P. Rameau. Un musician philosophe au siècle des Lumières. Paris: L'Harmattan, 2011.

KINTZLER, C. Jean-Philippe Rameau. Splendeur et naufrage de l'esthétique du plaisir à l'âge classique. Paris: Minerve, 1988.

LEGRAND, R. Rameau et le pouvoir de l'harmonie. Paris: Cité de la musique, 2007.

NIETZCHE, F. O Nascimento da tragédia ou Helenismo e pessimismo. Tradução de J. Guinsburg. São Paulo: Companhia Das Letras, 1996.

POUSSEUR, H. Apoteose de Rameau e outros ensaios. Tradução de Flo Menezes e Mauricio Oliveira Santos. São Paulo: Editora da UNESP, 2005.

RAMEAU, J-P. Traité de l'harmonie. Paris: Editions Robert Martin, 2009.

$\overline{\mathrm{BnF}, \mathrm{s} / \mathrm{d}}$ Démonstration du principe de l’harmonie (Éd. 1750). Paris: Hachette Livre

ROUSSEAU, J-J. Discours sur les sciences et les arts. In Euvres complètes. Tome III. Pléiade. Paris: Gallimard, 1964.

. Essai sur l'origine des langues. In Euvres complètes. Tome V. Pléiade. Paris: Gallimard, 1995.

\footnotetext{
Sobre o autor

Luis Felipe Netto de Andrade e Silva Sahd

Doutor em Filosofia pela UNICAMP e professor associado da Universidade Federal do Ceará-UFC.

E-mail: felipesahd@yahoo.com.br

Recebido em 16/07/2019

Aprovado em 15/10/2019

Como referenciar esse artigo
}

SAHD, Luis Felipe Netto de Andrade e Silva. A música como arte imitativa: da estética cartesiana à arte de expressar paixões. Argumentos: Revista de Filosofia. Fortaleza, ano 11, n. 22, p. 120-130, jul.-dez. 2019. 